\title{
EXPLORING THE CONCEPT OF UBUNTU IN RELATION TO DYING WITH DIGNITY IN PALLIATIVE AND HOSPICE CARE
}

\author{
Ntokozo Mnyandu \\ LLB LLM \\ Lecturer, University of KwaZulu-Natal
}

\begin{abstract}
SUMMARY
The Supreme Court of Appeal in Minister of Justice and Correctional Services $v$ Estate Stransham-Ford raised more questions than the answers it provided. However, of note is the enquiry it made regarding the implications of palliative care in relation to whether the criminality of physician-assisted suicide and physicianadministered euthanasia infringes a person's dignity. In response, this paper aims to reconstruct - through the lens of Ubuntu - our understanding of human dignity and draw links with how the values of compassion and survival, which underpin Ubuntu, enjoin us as a re-affirmation of human dignity, to strive towards making hospice and palliative care readily available. Ultimately, this is done for the benefit of providing constitutionally sound reasons for why greater emphasis should be placed on palliative and hospice care when it comes to dying with dignity. To this effect, a conceptual framework of human dignity that is based on Ubuntu is summarised. This is done for the purpose of properly aligning the understanding of the right to dignity to one that represents our constitutional dispensation and ethos. Flowing from this is an extract of the values of compassion and survival that underpin Ubuntu. These values are then used to gain a lucid perspective, as to why - in our pursuit of providing a dignified death for terminally ill patients - greater emphasis should be placed on hospice and palliative care.
\end{abstract}

\section{INTRODUCTION}

"The hour to part has come. I go to die, you go to live. Which of us goes to the better lot is known to no one, except the god.

The quality of life at the moment of death is informative to a judgment about whether a life is worth living. Presently, the law affords a person the right to act in accordance with such a judgment - albeit in a limited way. ${ }^{2}$ Developed by American law $^{3}$ and later adopted in South African jurisprudence, ${ }^{4}$ such a

The author would like to express his gratitude to Professor N Ntlama for her time and insightful comments.

Plato Apology, trans. Grube in Readings in Ancient Greek Philosophy: From Thales to Aristotle 2ed (2000) 130.

Stoffberg v Elliott 1923 CPD 148 par 149-150.

Re Quinlan 70 N.J. 10 (1976) 355 A.2d 64754.

Stoffberg $v$ Elliott supra 149-150. 
limited right exists only in respect of refusing life-sustaining interventions. ${ }^{5}$ It does not go as far as allowing a condemned person to seek assisted suicide. From this limitation, arise the calls for the possibility of patients to be allowed to obtain a lethal prescription that they could use to hasten their death - commonly referred to as physician-assisted suicide (PAS). Associated with this is a call for physician-administered euthanasia (PAE), which entails soliciting the aid of a physician in administering the lethal drug.

The discussion about assisted suicide (both PAS and PAE) has been a long and contested issue the world over, and opinions will differ for many hundreds of years to come. ${ }^{6}$ However, less debate takes place on what ought to happen before, that being the implementation of a comprehensive palliative and hospice healthcare service - and hence the need for this paper, which serves to provide constitutionally aligned perspectives in relation to why greater emphasis should be placed on palliative and hospice care when it comes to terminal illness. The focus is not on whether we should legislate on assisted suicide, but rather the paper seeks to strengthen the existing rallying call for a comprehensive palliative and hospice care system in South Africa. Since palliative and hospice care systems are seen as either alternatives to assisted suicide or as mechanisms that can be complemented by it - it becomes necessary to briefly elaborate on what assisted suicide entails.

When explained in detail, assisted suicide is a call for mechanisms to assist terminally ill patients to escape protracted suffering, discomfort, deteriorating health and the diminished privacy associated with institutional caring. ${ }^{7}$ To this end, the Supreme Court of Appeal in Minister of Justice and Correctional Services $v$ Estate Stransham-Ford ${ }^{8}$ recently left unanswered the call for a right to die with dignity. ${ }^{9}$ However, the very same court averred that the applicant ${ }^{10}$ who wanted a right to assisted suicide - Stransham-Ford - had actually died with dignity, surpassing his own expectations and predictions of an undignified death. The question then is what if there were systems in place to help negate this end-of-life suffering. Beneficence in the form of hospice and palliative care has been advanced as the system that could respond to end-of-life suffering, as it is not dependent on whether a right to assisted suicide exists since the need for it can be inferred from the right to health. ${ }^{11} \mathrm{~A}$ brief analysis of what constitutes hospice and palliative care now follows.

Broadly speaking, hospice and palliative care promote dignity in death. The former achieves this by controlling distressing symptoms like discomfort, while simultaneously providing emotional and spiritual support for the dying and their families. The latter is a medical subspecialty that aims to relieve

5 Ibid.

6 Minister of Justice and Correctional Services v Estate Stransham-Ford (531/2015) 2016 ZASCA 197 (6) par 1.

Biggs Euthanasia: Death with Dignity and the Law (2001) 95

(531/2015) 2016 ZASCA 197 (6).

Par 101.

Stransham-Ford v Minister of Justice and Correctional Services 2015 (4) SA 50 (GP).

11 Albertus "Palliative Care for Terminally III Inmates: Does the State have a Legal Obligation?" 2012 25(1) SACJ 74. 
suffering associated with unpleasant physical sensations - which often characterise terminal illness. With advances in these specialist care fields, the reality is that gains are already being made to ensure that the dying "live fully until they die". ${ }^{2}$ Wallis JA recently confirmed the same, when he averred that:

"It appears from it [evidence presented] that the spectra commonly conjured up of a helpless patient confined to a hospital bed and attached to an array of machinery is, in the vast majority of end-of-life situations, not what occurs, even with patients suffering from extremely grave diseases. It did not apply to Mr Stransham-Ford."

The above considered, the purpose of this paper was to reconstruct through the lens of Ubuntu - our understanding of human dignity and draw links with how the values of compassion and survival, which underpin Ubuntu, enjoin us as a re-affirmation of human dignity, to strive towards making hospice and palliative care readily available. Ultimately, this is done for the benefit of providing constitutionally sound perspectives on why greater emphasis should be placed on palliative and hospice care when it comes to dying with dignity.

To arrive at the aim of this paper, the author summarised a conceptual framework of human dignity based on Ubuntu. This was done to properly align the understanding of the right to dignity with one that represents our constitutional dispensation, ethos, and the lived experience of most South Africans. Flowing from this is an extract of the values of compassion and survival that underpin Ubuntu. These values are then used to gain a lucid perspective on why - in our pursuit of providing a dignified death for terminally ill patients - greater emphasis should be placed on hospice and palliative care. To begin, the author highlights the current plight in South Africa in respect of getting an efficient and comprehensive palliative and hospice care system readily available for those that depend on it.

\section{OVERVIEW OF THE PROBLEM}

According to the World Health Organisation (WHO), an estimated 40 million people are in need of palliative care and, of these, $78 \%$ live in low- and middle-income countries. ${ }^{14}$ This is despite the International Convent on Economic, Social and Cultural Rights Committee confirming that access to essential drugs - as defined by the WHO Action Programme on Essential Drugs $^{15}$ - is part of the minimum core content of the right to health. ${ }^{16}$ There are at least 14 palliative care medications that feature on the WHO Essential Drug List.

\footnotetext{
Putnam Hospice or Hemlock? (2002) 35.

Minister of Justice and Correctional Services v Estate Stransham-Ford supra par 36.

"Palliative Care Fact Sheet" August 2017 http://www.who.int/mediacentre/factsheet/fs402/ en/ (accessed 2017-10-30).

15 "WHO Model List of Essential Drugs March 2017" 6 June 2017 http://www.who.int /mediacentre/news/releases/2017/essential-medicines-list/en/ (accessed 2017-10-31).

16 "CESCR General Comment No. 14: The Right to the Highest Attainable Standard of Health (Art 12)" 11 August 2017 http:www.refwordl.org/pdfid/4538838d0.pdf (accessed 2017-1031).
} 
Although South Africa is seen as approaching integration, much more needs to be done. South Africa has well-established, non-governmental organisation services offering mainly hospice care, although not yet countrywide, and there are a few hospital-based services integrating palliative care into the formal healthcare sector. ${ }^{17}$ In May 2016, the Minister of Health, Dr Motsoaledi, appointed a National Steering Committee for Palliative Care to create "a revolution in healthcare through palliative care". ${ }^{18}$ Owing to this, a National Policy Framework for Palliative Care was approved in April 2017 by the National Health Council. ${ }^{19}$ This is an acknowledgement of the work already achieved, although the current plight facing South Africa in respect of a comprehensive palliative care health system begins to unravel when one considers the figures from the HPCA: just over $2 \%$ of public-sector hospitals have a proper palliative care service and only $4 \%$ of South Africans who clinically qualify for palliative care are actually receiving it. $^{20}$

\section{A CONCEPTUAL FRAMEWORK OF HUMAN DIGNITY BASED ON UBUNTU}

The discussion of assisted suicide turns on several issues and these frequently include a concern around the practicality and capacity of carrying out requests for assisted suicide, ${ }^{21}$ as well as its likely abuse, which is commonly referred to as the "slippery slope phenomenon". However, at the heart of the debate, is whether assisted suicide - as PAS or PAE - is an enforcement of the right to dignity or whether the practice would be an infringement of the same. ${ }^{22}$

To gain a better understanding of where our constitutional dispensation stands on this issue, it becomes prudent to examine what a right to dignity entails, and then draw in the African value of Ubuntu, which is analogous to human dignity. The focus will then shift back to look at the values and attitudes of the African community when it comes to the elderly and the sick.

It must be acknowledged that when considering any human rights issue, reference should be made to encompassing a "rounded view of society and not [being] confined to a section of it". ${ }^{23}$ To negate this potential hazard, the

17 Gwyther, Brennman and Harding "Advancing Palliative Care as a Human Right" 2009 38(5) Journal of Pain and Management 768.

18 Gwyther "National Policy Framework for Palliative Care" 8 September 2016 http://hpca.co.za/item/national-policy -framework-for-palliative-care (accessed 2017-11-01).

19 Hospice Palliative Care Association of South Africa "Congratulations All! A Palliative Care Policy Finds a Much Needed Place in South African Health System" 7 April 2017 http://www.hpca.co.za/news/congratulations-all-a-palliative-care-policy-finds-a-muchneeded-place-in-south-african-health-system-html (accessed 2017-10-31).

20 South African Medical Association "Med-eMail-Media Release: SA's Doctors Back Palliative Care - Not Euthanasia" 30 May 2015 http://www/samedical.org/cms/_uploader/view Article/ 91 (accessed 2017-10-31).

21 Par 67.

22 Jordaan "Human Dignity and the Future of the Voluntary Active Euthanasia Debate In South Africa" 2017 107(5) SAMJ 383

23 Minister of Justice and Correctional Services v Estate Stransham-Ford supra par 100. 
author has used the concept of Ubuntu, which has been applied by the judiciary as a constitutional value. ${ }^{24}$

\section{Exploring human dignity through the lens of Ubuntu}

"I believe in human dignity as the source of national purpose." 25

Section 10 of the Constitution of the Republic of South Africa, 1996 (hereinafter "the Constitution") provides that "everyone has inherent dignity". ${ }^{26}$ This section read with $\mathrm{s} 7$ provides a further buffer by imposing a negative and positive duty on the state to ensure that the right to dignity is respected and protected. ${ }^{27}$ Additionally, the Constitutional Court has repeatedly highlighted the significance of this right in our constitutional democracy; in one sitting O'Regan $\mathrm{J}$ averred that the "protection of human dignity is the touchstone of the new political order and is fundamental to the new Constitution". ${ }^{28}$ The right is valued highly and not only in South Africa as Dworkin points out that in Western political culture it features as being most important. ${ }^{29}$

Finding a comprehensive definition of human dignity is, however, an exacting undertaking, and it is so painstaking a task, that one constitutional law expert has equated it to an eternal quest. ${ }^{30}$ If one looks at the Constitutional Court's jurisprudence on human dignity, five crystallised definitions arise. Human dignity is seen as concerning: an individual as an end-in-herself, equal concern and equal respect, self-actualisation, selfgovernance, and collective responsibility for the material conditions for personhood. ${ }^{31}$ To this end, the Supreme Court of Canada in Law v Minister of Employment and Immigration ${ }^{32}$ expressed that human dignity is the selfworth and self-respect of a group or an individual. ${ }^{33}$ The Court went further to explain that human dignity is concerned with physical and psychological integrity and empowerment. ${ }^{34}$ O'Regan $\mathrm{J}$ explained a similar viewpoint when she noted that, "recognising a right to dignity is an acknowledgement

24 Himonga, Taylor and Pope "Reflection on Judicial Views of Ubuntu" 2013 16(5) PER 380.

25 Kennedy "Address of John F. Kennedy upon Accepting the Liberal Party Nomination for President, New York, September 14, 1960" (undated) https://www.jfklibrary.org/Research Research-Aids/JFK-Speeches/Liberal-Party-Nomination-NCY_19600914.aspx (accessed 2017-06-12).

26 The Constitution of the Republic of South Africa, 1996.

27 S 7(2).

S v Makwanyane 1995 (3) SA 391 (CC) par 329.

29 Dworkin Life's Dominion: An Argument about Abortion, Euthanasia and Individual Freedom (1995) 148.

30 Brennan "The Constitution of the United States: Contemporary Rectification" 19858 Univ. California Davis LR 12 .

31 Woolman "Dignity" in Woolman and Bishop (eds) Constitutional Law of South Africa 3ed (2013) 3(36).

32 [1999] 1 SCR 4971999 CanLII 675 (SCC).

33 Par 53.

34 lbid. 
of the intrinsic worth of human beings: human beings are entitled to be treated as worthy of respect and concern". ${ }^{35}$

From this, we can gather that human dignity has two meanings. First, it establishes that human beings have a sense of identity, self-concern, respect and consideration, which, when simplified, means a concern for one's moral worth (personhood). Second, it considers that humans are capable of modelling their own journey, albeit in cooperation and reciprocity with others. ${ }^{36}$ Biggs goes further by encapsulating personal autonomy in the first meaning of human dignity, where she claims that human dignity encompasses an opportunity to direct one's own conduct according to selfformulated convictions. ${ }^{37}$ This definition can be described as the physical and psychological integrity ${ }^{38}$ that the Supreme Court of Canada in Minister of Employment and Immigration alluded to.

When we express human dignity from the above definitions, we are in essence looking at a Western notion of dignity. The discussion that follows considers human dignity through an Ubuntu perspective - so as to present a definition of dignity that is set on the lived experience of most South Africans. ${ }^{40}$

A more promising concept of dignity found in the spirit of Ubuntu, ultimately holds that since survival and compassion are at the heart of African communities, then the physical and psychological integrity of an individual extends only insofar as it contributes to communal goals. ${ }^{41}$ This recognises that communal relationships help shape one's own journey and that these relationships are important considerations in the pursuit and achievement of the fullness of one's moral worth. ${ }^{42} \mathrm{~A}$ few Constitutional Court cases are considered in order to make this point:

Khosa $v$ Minister of Social Development: ${ }^{43}$

"wealthier members of the community view the minimal well-being of the poor as connected with their personal well-being and the well-being of the community as a whole."

Port Elizabeth Municipality v Various Occupiers: ${ }^{44}$

Makwanyane par 328.

36 Reaume "Law v Canada (Minister of Employment and Immigration)" 2006 18(1) Canadian Journal of Women and the Law 161.

37 Biggs Euthanasia: Death with Dignity and the Law 145

38 Law $v$ Minister of Employment and Immigration supra par 53.

39 lbid.

40 Mokgoro and Woolman "Where Dignity Ends and Ubuntu Begins: An Amplification of, as well as an Identification of a Tension in, Drucilla Cornell's Thoughts" 2010 25(2) SAPL 402.

The authors contend that it hardly seems controversial to ground the South African Constitution in the lived experience of South Africans - so long as an ubuntu-based reading does no violence to the text.

41 Metz "Ubuntu as a Moral Theory and Human Rights in South Africa" 201111 African Human Rights Law Journal 540.

42 lbid.

432004 (6) SA 505 (CC).

442005 (1) SA 217 (CC) par 37. 
"It (the spirit of Ubuntu) combines the individual right with a communitarian philosophy. It is a unifying motif of the Bill of Rights, which is nothing if not a structured, institutionalised operational declaration in our evolving new society of the need for human interdependence, respect and concern."

"It is not only the dignity of the poor that is assailed when homeless people are driven from pillar to post in a desperate quest for a place where they and their families can rest their heads. Our society as a whole is demeaned when state action intensifies rather than mitigates their marginalisation (author's own emphasis).

The courts' account of human dignity appears to describe dignity as a collective good; one that is set on recognising one's personhood on condition of how one relates to others. This account of human dignity is an Ubuntu-based reading of the provisions of the basic law, which gives a distinctly Southern African perspective.

To gain an understanding of the role of Ubuntu, starting with a literal translation of Ubuntu is prudent, which purports that "umuntu ngumuntu ngabantu" or "a person is a person because of other people". Ubuntu is an African worldview that constitutes a way of life for those that ascribe to it. ${ }^{46}$ Emphasis is placed on the "individual as being embedded in a community" 47 - as opposed to "an individual as a right-bearer". ${ }^{48}$ Flowing from Ubuntu are values of group solidarity, survival, compassion, respect and dignity. ${ }^{49}$ Ubuntu embraces the same two meanings that underpin human dignity. First is the assertion that "a person is a person", which is a recognition of one's inherent moral worth. Second, the claim that "a person is because of others" recognises that communal relationships with others, plays an important part in shaping one's moral worth. The understanding here is that the second meaning informs the first, in that flowing from a communal relationship is the fullness of one's moral worth. ${ }^{50}$ A similar view was put forward by Langa CJ in MEC for Education: KwaZulu-Natal v Pillay, ${ }^{51}$ where he noted that:

"An individual human person cannot develop and achieve the fullness of

his/her potential without concrete act of relating to other individual persons.

The essence of Ubuntu and human dignity is then the recognition of the existence of others and their impact on the lives of the individuals around them. It represents a duty to think of oneself as being bound up with

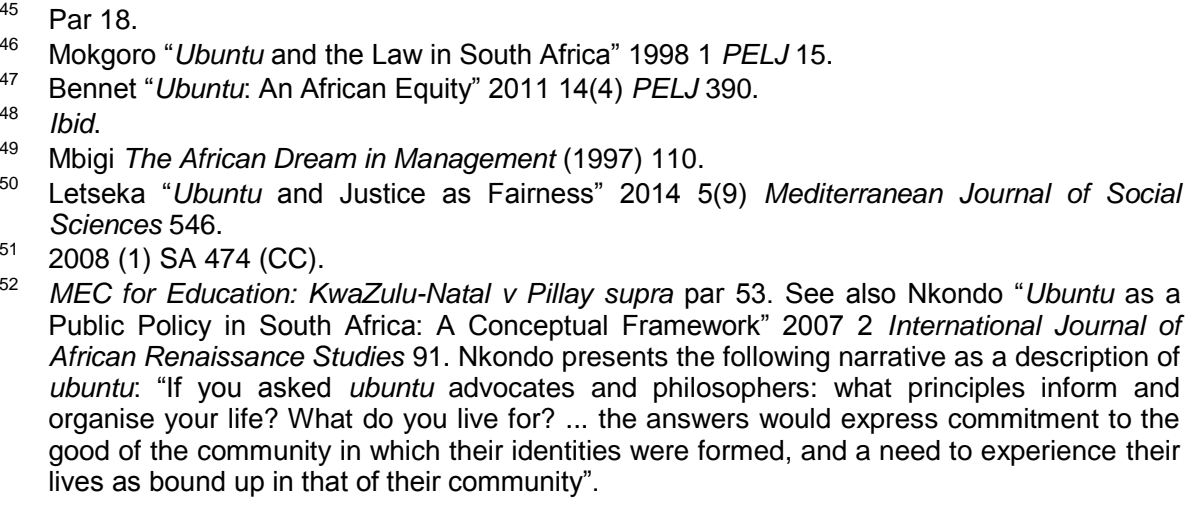

52 MEC for Education: KwaZulu-Natal v Pillay supra par 53. See also Nkondo "Ubuntu as a Public Policy in South Africa: A Conceptual Framework" 20072 International Journal of African Renaissance Studies 91. Nkondo presents the following narrative as a description of ubuntu: "If you asked ubuntu advocates and philosophers: what principles inform and organise your life? What do you live for? ... the answers would express commitment to the good of the community in which their identities were formed, and a need to experience their lives as bound up in that of their community". 
others. ${ }^{53}$ It manifests in recognising the intrinsic worth of every individual in the community - from infants to the dying - because "the life of another is as valuable as one's own". ${ }^{54}$ A former Justice of the Constitutional Court said this about Ubuntu:

"[t]he idea of Ubuntu, as a worldview, encompassing respect and the value placed on the basic humanity of a human being, would elude if the desire to pin it down to a single, well-defined concept. Because this concept translates into communal practices based on interconnectivity and does not view individual well-being outside of the communal well-being, its contemporary utility becomes particularly difficult."

The discussion below examines two of the founding values of Ubuntu survival and compassion. This is done in an attempt to pull in the final assumption that, through survival and compassion, Ubuntu (as an affirmation of human dignity) enjoins us to make readily available hospice and palliative care for people living with terminal illness.

\section{The value of survival}

Of the five values said to underpin Ubuntu, at the heart is the significance placed on survival. Survival can be described as the ability to live and exist despite an ordeal or difficult circumstances. The ability to draw strengths from individuals has long been at the heart of African communities. Within these communities, there is a collective effort of pooling scarce resources and maximising the same in order to survive poverty, illness and oppression. This manifestation of collectivism and collaboration enables the community (for the sake of survival) to be resilient in the face of adversity and to ensure that despite an effort to deprive them of human qualities, they emerge still human. $^{56}$ The value of group solidarity for survival issues represents the coexistence and co-dependence of community members. The dominant theme then is that "the life of another person is at least as valuable as one's own", 57 and each member, although young, disabled, elderly or terminally ill, has a role to play in ensuring the survival of the community. It is for this reason that every effort is directed at the sustenance of each member. This communal and concerted effort is illustrated in a well-conceived practice of Ubuntu, ukwenana, which is the act of giving unselfishly without expecting anything in return.

The same principle can be ascribed to hospice care, which aims to ensure that the terminally ill live fully until they die. The recognition here is that until you cease to be a member of a group by virtue of whether you are alive or not, you too have a role to play in ensuring the survival of the group. The elderly and the terminally ill are entrusted with imparting wisdom to the group. They are enjoined to share their end-of-life experiences so that future

53 Nkondo 20072 International Journal of African Renaissance Studies 90.

$54 S$ v Makwanyane supra par 225. See also Hoctor "Dignity, Criminal Law and the Bill of Rights" 2004121 SALJ 315. The author speaks of this dominant theme of ubuntu as being entirely consistent with the dignity principle.

55 Mokgoro "Ubuntu, the Constitution and the Right of Non-Citizens" 2010 21(2) Stell LR 225.

56 Tutu No Future Without Forgiveness (2002) 31.

57 Nkondo 20072 International Journal of African Renaissance Studies 90. 
generations know how to better approach or prepare for their final hours. If death is, however hastened, it deprives the group of the ability to draw strength from these individuals, and likewise, it deprives the dying of the chance to continue their relations with the community and to thus re-affirm their own dignity. Furthermore, terminally ill patients must come to terms with the thought that their death is at hand, and the idea in itself is unnerving which creates a perceived loss of dignity. Hospice care works to remedy this through its support system, in the form of education, encouragement and restoration of hope.

Behrens, in his commentary on why the argument for sufficient palliation fails, inter alia points to the loss of independence as a major contributing factor to this perceived loss of dignity. ${ }^{58}$ While this is true, there is a remedy, as hospice care works to make small adjustments in the daily lives of the terminally ill in order to offer patients as many options as possible for restoring individual autonomy, sense of self, and personhood. ${ }^{59}$ Hospice care also understands that we should not forget the inherent moral worth of the members concerned, by making it seem as if they should live for others - despite the agony sometimes associated with the final hours of life. Instead, hospice care re-affirms their dignity by making readily available palliative care and psychological, spiritual, social and bereavement services - so that all the symptoms of terminal illness are effectively managed.

\section{The value of compassion}

"Ubuntu is characterised by such values as caring, reciprocity, sharing, compassion, hospitality, cohabitation, cooperation and tolerance."

The ability to reach out to all members of the community comes from another value of Ubuntu: compassion. Compassion is a human quality of having concern for the sufferings of others and wanting to be of assistance to them. Through the value of compassion comes an understanding that all human beings share a common and communal responsibility for each other - because they are all interconnected. Compassion is critical in ensuring that the group maintains its interconnectedness because individuals are always longing to be of assistance to others. Compassion can, therefore, be seen as a driving force behind the group's ability to draw strength from each other, in pursuit of survival. When it comes to end-of-life situations, individuals can show compassion by offering their time and effort in terms of hospice and palliative care, to terminally ill members of the group, so that the core and strength of the group is being maintained - as this is the best chance of survival for the group. Compassion allows the dying and his or her families to continue with the ideals of communal relationship, and this only works to re-affirm the dignity of everyone involved. Compassion is seen as a vital

58 Behrens "Assisted Dying: Why the Argument from Sufficient Palliation Fails" 2017 36(2) South Africa Journal of Philosophy 192.

59 Bunt and Du Plessis "What Patients Want: A Qualitative Study of Palliative Care Experiences of HIV and Aids Patients and their Families" 2015 2(2) African Journal of Physical, Health Education, Recreation and Dance 354.

60 Khoza Let Africa Lead (African Transformation Leadership for $21^{\text {st }}$ Century Business) (2006) xxii. 
aspect of palliative care. ${ }^{61}$ The gentle and caring manner in which caregivers establish an understanding and contact with patients helps to restore their sense of self and personhood.

\section{ON ONE'S DEATH BED: AVAILABLE RECOURSE}

The Supreme Court of Appeal in Minister of Justice and Correctional Services $v$ Estate Stransham-Ford ${ }^{62}$ raised more questions than the answers it provided. However, specific to this discussion is the enquiry it made regarding the implications of palliative care for whether the criminality of PAS and PAE infringes a person's dignity. ${ }^{63}$

\section{Stransham-Ford: ${ }^{64}$ death with dignity}

\section{Background facts}

Stransham-Ford was diagnosed with prostate cancer on 19 February $2013 .^{65}$ The cancer became progressive and by 13 March 2015 had spread to his lymph glands and would eventually reach stage four by the time of his death. ${ }^{66}$ On 17 April 2015 (the date of his High Court application) Stransham-Ford maintained a pessimistic prognosis on his condition, as he believed unbearable suffering would accompany his death, and, as a result of an excessive use of opiates, he would become oblivious to the care of his loved ones. ${ }^{67} \mathrm{~A}$ day later, he had maintained most of his speech but required the assistance of his former wife in clarifying the same. She relayed to his physician, Dr Cameron Bruce, that he was enquiring about whether he could change his mind about the need for assisted suicide. ${ }^{68}$ On 21 April 2015, Stransham-Ford appeared to suffer from an acutely disturbed state of mind, but nevertheless could get up and use ablution facilities. ${ }^{69}$ After slipping into a coma two days earlier, he succumbed to his terminal illness on 30 April $2015 .^{70}$

It is common cause that on 12 March 2015 - six weeks before his death Stransham-Ford had continued with his law practice unabated, suffering from mild pelvic pain, which routine painkillers managed. ${ }^{71}$ However, his condition worsened three days later, and, as a result, he was admitted to Victoria Hospital, suffering from severe abdominal pain. From 25 March 2015, the assistance of a palliative care nurse from St Luke's Hospice was

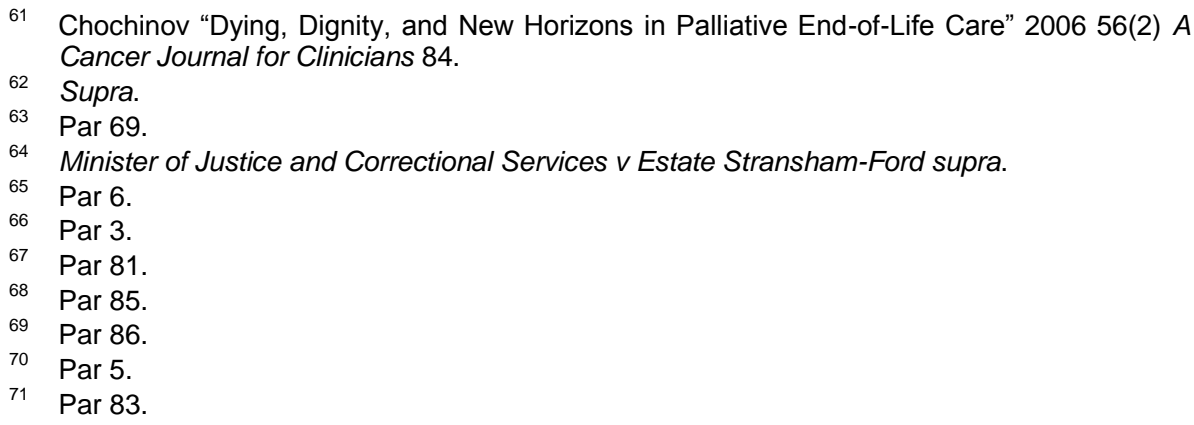


sourced - as well as the palliative expertise of Dr David Cameron. Despite this, in his replying affidavit, Stransham-Ford averred that he continued to suffer from severe pain, nausea, and loss of appetite, among other symptoms. The Supreme Court of Appeal in Estate Stransham-Ford found that this depiction of his final illness "bore little resemblance to reality". ${ }^{72}$ It is important to point out that, contrary to his affidavit of 21 April 2015 (ten days before he died), he was able to get up and use ablution facilities. This suggests that his end-of-life suffering was well managed and that his other symptoms were sufficiently attended to, given the precarious circumstances. To this effect, the supplementary report of Dr David Cameron, which was based on the notes of Dr Cameron Bruce, found that Stransham-Ford's death was not frightening or undignified. The report reads:

"Dr Bruce commented that, together with the assistance of community nurses from Luke's Hospice, he had been able to provide palliative care to RSF [Robert Stransham-Ford] in the setting of his ex-wife's home. This had enabled those who had been separated in the past to be brought together in a very meaningful way. His symptoms were managed effectively enough for him to be able to die in a homely atmosphere surrounded by family and friends who cared for him. The impact of palliative care surpassed his expectations and defied his own predictions of a frightening, impersonal and undignified death."

\section{The many facets of hospice and palliative care}

The medical philosophy of hospice care does not seek to prolong life by means of human intervention - nor does it aim to hasten the dying process unnaturally. ${ }^{74}$ Instead, the dying process is left to take its natural course, with a primary focus on giving supportive care to people in the final phase of a terminal illness. The idea behind providing supportive care is to ensure that the dying live fully until they die - as was first intended by the founder of the modern hospice movement, Dame Saunders. ${ }^{75}$ To live fully until one dies is to have readily available psychological, spiritual, social and bereavement services for the dying and their families.

As previously mentioned, a right to a dignified death is really a call for inter alia mechanisms to assist patients to escape protracted suffering and discomfort. Hospice care aims to remedy this by enhancing bodily functions and alleviating the stress and the lack of privacy, which is often synonymous with institutional caring. ${ }^{77}$ Comfort plays a significant role in this endeavour and is often conveyed through support and encouragement. ${ }^{78}$ Hospice care often consists of a team of nursing staff and counsellors who volunteer their

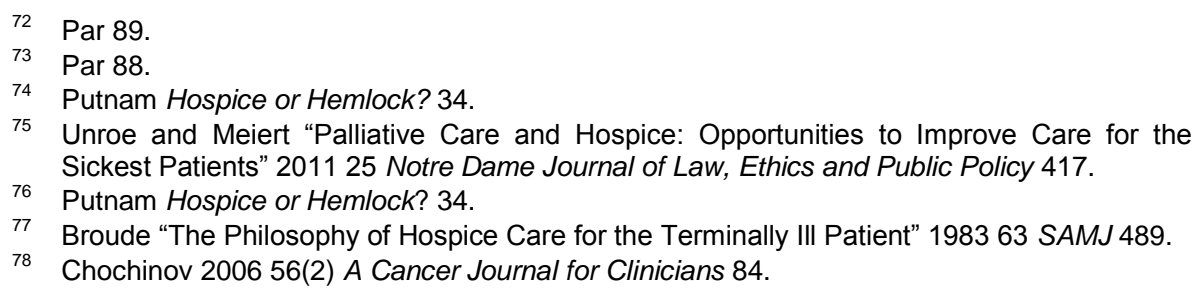


time and expertise to patients and their families, with the aim of preparing them emotionally and spiritually for death. ${ }^{79}$

The benefits of hospice care extend beyond the dying and their families. Hospice care specialists work to complement the efforts of doctors by attending to the discomfort, anxiety and agony that is often synonymous with a terminal illness. This enables doctors to direct their attention at working out an appropriate course of treatment - without having to spend most of their time listening to the fears of patients and family and having to help them support one another. ${ }^{80}$ However, hospice care is only appropriate when terminal illness sets in and when curative treatments are no longer beneficial. ${ }^{81}$ In every other situation, palliative care should be made readily available.

On the other hand, according to the World Health Organisation, there is more to palliative care than just pain relief. At its heart is "improving the quality of life of patients and families who are facing problems associated with life-threatening illnesses". ${ }^{22}$ According to a Draft Bill submitted to the Minister of Justice for the End-of-Life Decisions Act $1998,{ }^{83}$ palliative care is the treatment of patients who are at the end-stage of their illness - with the object of relieving emotional, physical and psychosocial suffering, and to maintain personal hygiene. ${ }^{84}$ Additionally, like the staff involved in hospice, palliative care specialists help patients and their families to determine an appropriate course of treatment. Stransham-Ford was one person who benefited from the services of hospice and palliative care and from the discussion below it would seem that these services contributed positively to the manner in which he spent his final days.

\section{A MORE PROMISING CONCEPT OF DYING WITH DIGNITY: UBUNTU IN PALLIATIVE AND HOSPICE CARE}

A definition of human dignity has many aspects to it, and therefore it is not a concept that can be applied universally without some form of introspection and relativism. To this end, Lord Hoffmann explained, "of course we share a common humanity", ${ }^{85}$ however, "different communities will, through their legislature and judges adopt, the answers, which they think suit them". ${ }^{86}$ Essentially, he was saying that our view of human dignity should be culturally determined. For a South African perspective on human dignity and the attitude and values we attach to the sick and elderly, the author evokes the value of Ubuntu. The discussion that follows examines the analogous nature of Ubuntu and human dignity.

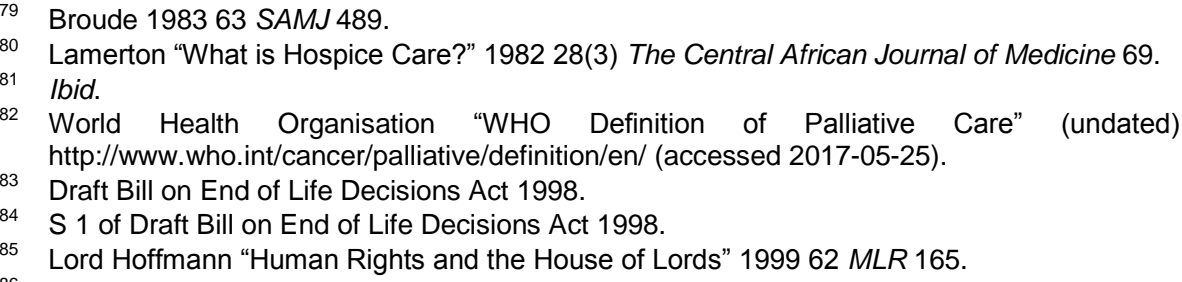


In Dawood v Minister of Home Affairs, ${ }^{87}$ the Constitutional Court said that:

"Human dignity ... informs constitutional adjudication and interpretation at a range of levels. It is a value that informs the interpretation of many, possibly
all, other rights."

Similarly, Ubuntu has been qualified as a constitutional value, in that it is used as a basis for the interpretation of the Bill of Rights. ${ }^{89}$ The reason for this is that Ubuntu has been found to permeate the Constitution generally and more particularly in Chapter Two, - which embodies the entrenched fundamental human rights. ${ }^{90}$ Furthermore, Ubuntu is seen as a "golden thread" that runs across cultural lines. ${ }^{91}$ This is also, why a more promising concept of dignity based on Ubuntu is being relayed.

Moreover, Langa $\mathrm{J}$ describes Ubuntu in Makwanyane ${ }^{92}$ as a concept that recognises "a person's status as a human being, entitled to unconditional respect, dignity, value and acceptance from the members of the community..." McCrudden offers a similar view when it comes to human dignity. In his explanation of what he calls the "second element of human dignity", he suggests that one's intrinsic worth has to be recognised and respected by others. ${ }^{94}$ The similarity here lies in the qualities that Ubuntu and human dignity recognise in humans by virtue of their existence - the quality of having moral worth that is deserving of respect.

Lastly, the break into the new constitutional dispensation shows further similarities between the role of Ubuntu and human dignity. National unity and reconciliation hinged on the spirit of Ubuntu, which became decisive in breaking the chain of untold suffering and injustices of the past into a new, albeit shorter, chain of solidarity. ${ }^{95}$ Equally, Botha finds that human dignity was also central to a breakaway from a history of totalitarianism and discrimination. ${ }^{96}$

\section{Stransham-Ford: a case in point}

The Stransham-Ford case is not unique. It speaks of a man who had enjoyed a good practice as an advocate, who lived well into his sixties, only to have to come to terms with the thought that perhaps the time to die had come. The agony of living with stage four cancer is well documented, and thus Stransham-Ford's progressive cancer and associated suffering would have done very little to abate the terrifying prospect of a frightening death. Nevertheless, he forged ahead with life and continued with his practice

2000 (3) SA 936 (CC).

Dawood v Minister of Home Affairs supra par 35.

Himonga et al 2013 16(5) PER 430.

S v Makwanyane supra par 237.

S v Makwanyane supra par 306.

$S$ v Makwanyane supra.

S v Makwanyane supra par 224.

4 MucCrudden "Human Dignity and Judicial Interpretation of Human Rights" 2008 19(4) The Journal of International Law 679.

95 Epilogue, Interim Constitution of the Republic of South Africa, 1993.

96 Botha "Human Dignity in Comparative Perspective" 20092 Stell LR 177. 
unabated. However, during mid-March 2015, when the symptoms of his terminal illness became more apparent, the thought of an undignified death could have driven his motivation to seek out assisted suicide. However, once the services of palliative care experts became available, it seems that his symptoms were effectively managed - to the extent that he could use the ablution facilities on his own. This could also have played a role in his enquiry about whether he could change his mind about going through with assisted suicide altogether. In the end, his death was not a frightening experience - as he died in the care of his loved ones, was able to use the ablution facilities, his pain was effectively managed, and his death was dignified. A significant contribution to this outcome can be attributed to the hospice and palliative care interventions he received after being admitted to Victoria Hospital. However, judging from his responding affidavit, these interventions did very little to help him. To the contrary, the Supreme Court of Appeal pointed out that his averments bore little resemblance to reality, ${ }^{97}$ and that there was a positive contribution from the hospice and palliative care teams.

Stransham-Ford sought an order in the High Court, to the effect that no criminal, civil or disciplinary liability should arise from the assisted administration or the provision of a lethal agent, ${ }^{98}$ and he argued that such an order would allow him to die with dignity. The High Court ultimately found there is no dignity in having severe pain, being unaware of one's surroundings and loved ones, and not being able to care for one's hygiene. ${ }^{99}$ However, the Supreme Court found that Stransham-Ford had died a dignified death.

The following is a reflection on the concept of Ubuntu and the values of survival and compassion - with particular reference to Stransham-Ford's dying with dignity in a palliative and hospice care setting.

In the previous sections, human dignity and Ubuntu were expressed as bearing two meanings. The first holds that human beings have an inherent moral worth, and second that one's relationship with others helps to bring this moral worth to fullness. Alas, human dignity does not fully capture how one should relate to others, but Ubuntu, which is analogous to human dignity, goes into detail on this. To this end, the underpinning values of survival and compassion are important considerations when it comes to one's expected communal relationship with others. Specific to this discussion, it has been observed that through the concern of the well-being of others, an individual can reach out and be of assistance to the dying, and this action of compassion in turn helps the community, for the sake of survival, to be resilient in the face of terminal illness. One might argue correctly that a dying person who is in grave agony cannot relate to others and that their sense of moral worth becomes diminished and ultimately their dignity is infringed. This is the same argument advanced by StranshamFord. However, with advances in palliative medicine and the proliferation of hospice care, a dying person need not die while suffering and being in discomfort. Through the values of compassion and survival - which in this

97 Minister of Justice and Correctional Services v Estate Stransham-Ford supra par 89.

98 Par 3.

$99 \quad$ Par 15. 
instance are expressed in palliative and hospice care - people can reach out and have communal relationships with others, and, in so doing, they reaffirm the dignity of everyone involved.

Attention to these measures achieves the re-affirmation of dignity in two respects. First, when hospice and palliative care intervene in the final stages of terminal illness, they give the dying an opportunity to engage with others, to be cared for, to have someone with the necessary skills and time to listen to one's fears and anxiety, to have loved ones who were once separated reunited by a common goal, and to relate to others. This, in turn, expresses a willingness to receive compassion, to let the dying process take its natural course, to be resilient in the face of adversity, and ultimately to survive. Second, family members are given an opportunity to be a part of the solution, and they give their time and effort to manage the suffering and discomfort of the dying. Hospice and palliative care specialists are also given the time and space to contribute positively to the dying - through support, encouragement, education and innumerable acts of kindness - to relate to them and ultimately to re-affirm their moral worth and dignity.

\section{CONCLUSION}

This paper looked at human dignity through the lens of Ubuntu. As a result, it was highlighted that like human dignity, Ubuntu is an important consideration when it comes to the interpretation of the Bill of Rights. In this way, it became evident that Ubuntu and human dignity are analogous, in that inter alia they represent the same two meanings. The first is an understanding that human beings have a sense of moral worth and second one's moral worth is brought into fullness by a communal relationship with others. This means that human dignity is affirmed by the way, in which we relate to others in the community. One such way is to make readily available hospice and palliative care. To support this assertion the author referred to the values that underpin Ubuntu: survival and compassion. Survival is the ability to draw strength from other members of the community, in order to withstand difficult circumstances. Hospice care gives the community the chance to draw strength from terminally ill patients. Through the innumerable displays of kindness in terms of providing comfort and support to the terminally ill, the afflicted can spend their final hours living as opposed to dying - and hence they are able to relate longer to other members of the community. The ability to reach out derives from the value of compassion. Through compassion, we ensure that the terminally ill can escape from the agony of the final hours and can re-affirm the dignity of those relating to them as well as their own through a process of dying that is bearable and has reduced discomfort.

The paper has provided an understanding of human dignity from the perspective of Ubuntu, from which we realise that to re-affirm our dignity as well as the dignity of the dying - we ought to focus our attention on making readily available hospice and palliative care services. Thabo Mbeki reflected on this point more accurately when he said that the age-old spirit of Ubuntu enjoins every member of the community to act in solidarity with those in dire circumstances. 